\title{
LIVROS DIDÁTICOS DE HISTÓRIA: entrecruzando leituras de imagens e orientações editoriais nas décadas de 1970 e 1980
}

\author{
João Batista Gonçalves Bueno* \\ Arnaldo Pinto Junior ${ }^{* *}$ \\ Maria de Fátima Guimarães ${ }^{* * *}$
}

\section{Resumo}

Neste artigo abordamos as mudanças e permanências nas formas de editoração de textos escritos e imagens impressas nos livros didáticos de História. Analisamos algumas obras produzidas por diferentes autores nas décadas de 1970 e 1980, dentre os quais: Sérgio Buarque de Holanda, Antonio José Borges Hermida, Gilberto Cotrim e Álvaro Duarte Alencar. Reconhecemos que a partir da década de 1970 foram estabelecidos novos padrões editoriais para os livros didáticos de História, os quais alteraram as formas de apresentação dos textos escritos na relação com as iconografias impressas. Os diferentes procedimentos de leituras das imagens estabelecidos desde então constituíram saberes editoriais e escolares que serviram de base teórica e procedimental para desenvolvimento de propostas que emergiram nas obras didáticas produzidas nas décadas posteriores. Esperamos, com este artigo, contribuir para a construção de práticas de leitura de imagens que possibilitem a fruição, o entendimento e a contextualização das informações que se relacionam ao uso de documentos visuais no ensino de História. Buscamos a valorização de procedimentos didáticos de leitura que permitam a construção, pelos professores e alunos, de interpretações pluridimensionais sobre as imagens como documentos históricos.

Palavras-chave: Livro didático. Ensino de História. Imagens visuais. Fontes documentais.

\footnotetext{
* Doutor em Educação Universidade Estadual de Campinas. Professor da Universidade Estadual da Paraíba. Email: apjbrasil@hotmail.com

** Doutor em Educação Universidade Estadual de Campinas. Professor da Universidade Federal do Espírito Santo. joaobgbueno@hotmail.com

*** Doutora em Educação pela Universidade Estadual de Campinas. Professora da Universidade São Francisco. mfgbueno@uol.com.br
} 


\title{
DIDACTIC BOOKS OF HISTORY: interweaving the practices of reading visual images and the editorial orientation between the decades of 1970 and 1980
}

\begin{abstract}
In this article we have studied the changes and permanence in the editorial forms of written texts and visual images published in didactics books of History. We have analysed works that were produced by different authors in the 1970 and 1980 decades: Sérgio Buarque de Holanda, Antonio José Borges Hermida, Gilberto Cotrim and Álvaro Duarte Alencar. We acknowledge that as from the 1970 decade it was established new editorial patterns for the didactic History books, which altered the ways of presentation of written texts towards the visual images. The different procedures of reading the visual images established until then, constituted editorial and scholar knowledge that served as theorical and procedural basis for the development of proposes that emerged on the didactic works produced on the decades afterwards. We expect to contribute with this study for the construction of visual images reading practices that make possible the flow, the understanding and the contextualization of information that relate the usage of visual documents in the teaching of History. We look for the empowerment of the didactic procedures of reading that allows the construction, by teachers and students, of pluridimensional interpretations about the visual images as historical documents.
\end{abstract}

Keywords: Didactic books. History teaching. Visual images. Documents.

Neste artigo analisamos alguns exemplares de livros didáticos de História produzidos entre as décadas de 1970 e 1980, com o intuito de focalizar como os autores e editores propuseram metodologias de leituras de imagens visuais ${ }^{1}$ para o ensino dessa disciplina escolar, porque estas nortearam as bases conceituais e procedimentais que serviram para a elaboração das metodologias apresentadas na atualidade. Retomando as contribuições teóricas de pesquisadores da área (BITTENCOURT, 2001; BUENO, 2011; GATTI JUNIOR, 1998; MUNAKATA, 1997), identificamos nas obras analisadas as referências de produções editoriais para os livros didáticos de História publicados nas décadas seguintes. O padrão editorial que passou a vigorar nos livros didáticos, desde então, se caracterizou pela apresentação simultânea, em uma mesma página, de textos escritos sintéticos entre imagens visuais coloridas. Além disso, tais livros assumiram formatos diferentes dos produzidos nas décadas anteriores (MÁSCULO, 2008; PINTO JR., 2010); suas dimensões foram ampliadas e a qualidade dos papéis utilizados na impressão melhorou.

\footnotetext{
${ }^{1}$ Utilizaremos, durante o desenrolar de todo o texto, o termo imagens visuais e seu sinônimo iconografias, pois reconhecemos que as sociedades modernas têm reduzido o significado da palavra imagem apenas para sua característica de evidência visual (ver, para tal, DEBORD, G., 2000) No entanto, é importante lembrarmos que a palavra "imagem" pode assumir diferentes conotações e sentidos. Ainda, segundo Aumont J.: "As imagens têm inúmeras atualizações potenciais, algumas se dirigem aos sentidos, outras unicamente ao intelecto, quando se fala do poder que certas palavras têm de "produzir imagem", por uso metafórico, por exemplo. Convém, portanto, dizer em primeiro lugar que, sem ignorar essa multiplicidade de sentidos, aqui só será considerada uma variedade de imagens, as que possuem forma visível, as imagens visuais” (2001, p. 8).
} 
A partir da década de 1970, o uso de recursos audiovisuais na educação foi extremamente valorizado. Sendo assim, os projetos editoriais dos livros didáticos começaram a se pautar pelas propostas de desenhos de instrução defendidas por Robert M. Gagné e J. Briggs Leslie $^{2}$. No período privilegiado, as teorias psicopedagógicas que ancoravam tais projetos editoriais baseavam-se em concepções da psicologia experimental da aprendizagem, das teorias da comunicação, das análises de sistemas, da cibernética e da psicologia experimental da percepção (FERREIRA; SILVA JR., 1975, p. 91).

\section{A Coleção Sérgio Buarque de Holanda}

A primeira coleção que focalizamos foi idealizada pelos seguintes autores: Sérgio Buarque de Holanda, Carla de Queiroz, Sylvia Barboza Ferraz, Virgílio Noya Pinto e Laima Mesgravis. Dentre os livros didáticos de História editados na década de 1970, os dessa coleção destacavam-se em decorrência do aprimoramento gráfico, da quantidade de imagens, do tipo de encadernação e da qualidade do papel que utilizavam (MÁSCULO, 2008). A concepção de ensino de História dessa coleção priorizava o aporte teórico que parte de processos socioeconômicos, destacando ainda temáticas que apresentavam diferentes aspectos culturais das sociedades abordadas em seus diferentes capítulos. Esses autores valorizavam a cultura erudita; em alguns trechos das obras trabalhavam com outras manifestações culturais, identificadas como folclóricas.

Abordamos, neste estudo, privilegiadamente dois volumes da Coleção Sérgio Buarque de Holanda. O primeiro era destinado às $5^{\mathrm{a}}$ e $6^{\mathrm{a}}$ séries do primeiro grau, com o título História do Brasil: da independência aos nossos dias. O segundo volume era destinado às $7^{\mathrm{a}}$ e $8^{\mathrm{a}}$ séries do primeiro grau, com o título História da Civilização. Os exemplares abordados foram

\footnotetext{
${ }^{2}$ Segundo Oliveira (1983, p. 94), "Gagné e Leslie são autores do livro denominado Principles of instructional design, de 1974, o qual é considerado como a obra mais completa que descreve a produção de materiais e conteúdos de instrução programada. Esse livro apresenta os conceitos, os esquemas, os modelos ou metodologias denominados "desenhos de instrução". Tais concepções descrevem que o processo de aprendizagem ocorre por meio de três grandes categorias. A primeira compreende as seguintes fases: ganhar atenção do aluno mediante uma pergunta provocativa ou alguma coisa significativa (imagem); em seguida, demonstra-se para o aluno o que ele vai aprender ou para que ele pode utilizar esse conhecimento. A partir de então, explica-se qual é a relação que esse novo conhecimento apresenta com o que ele já conhece. A segunda categoria denomina-se desempenho. Nessa fase o professor deve apresentar o novo conhecimento, exemplificando-o através de gráficos, textos, simulações, estudos de caso, etc., os quais devem explicar qual é a função desse novo conhecimento. Posteriormente, o professor deve oferecer situações para a aplicação do conhecimento adquirido, descrevendo para o aluno o seu grau de acerto - feedback. A terceira categoria compreende a avaliação através de testes, os quais criam uma sequência de atividades que vão aumentando em grau de dificuldade. Assim, os autores acreditam que o aluno pode realizar a transferência do conhecimento que é adquirido para outras situações ou exercícios.
} 
editados pela Companhia Editora Nacional, em $1972^{3}$. Ao analisarmos a composição gráfica das páginas dessa coleção didática, deparamo-nos com os critérios que balizaram sua organização e o seu projeto gráfico. Os subtítulos foram impressos com letras em caixa alta, em cores diferentes do texto explicativo. O espaço entrelinhas dos textos escritos era simplificado, mas satisfatório para a leitura. Tais textos foram diagramados em colunas e reduzidos, ocupando, assim, pouco menos da metade da página. As colunas de textos variavam nas posições das páginas, às vezes, apareciam na coluna da direita ou na da esquerda. Propomos que esse recurso foi utilizado para estabelecer uma relação de proximidade entre os textos, quando o livro estivesse aberto sobre as carteiras dos alunos. No espaço restante da página que se contrapunha aos textos, foram impressas as imagens, os mapas ou os infográficos. O vocabulário utilizado foi adaptado à idade dos alunos e os espaços em branco faziam parte da composição, servindo para dar destaque às imagens visuais ou aos textos. Quando visualizamos a página na sua totalidade, percebemos que a diagramação utilizada criou imagens visuais compactas (manchas gráficas), deixando-as mais agradáveis ao olhar. Muitas páginas dos livros analisados exibem boxes, os quais foram destacados com cores amarelas. Estes serviam para apresentar os textos, que tinham por objetivo aprofundar os conceitos que eram trabalhados no texto explicativo principal. As páginas eram compostas, na sua maior parte, por uma, duas ou três imagens visuais coloridas, baseadas em reproduções de pinturas históricas, fotografias de lugares públicos ou de edifícios de diferentes estilos arquitetônicos, mapas e infográficos.

Na página 18 (Figura 1) do livro História do Brasil: da independência aos nossos dias, temos a reprodução de uma fotografia apresentando uma técnica de composição das imagens visuais que já era muito utilizada à época na editoração de revistas ilustradas, livros infantis e outros tipos de publicação impressa. Essa reprodução fotográfica teve sua impressão "sangrada"4 na parte superior, com as outras três margens definidas. Ela é colorida e ocupa pouco mais de um terço do espaço de impressão da página. Tal diagramação tinha por mote atrair os olhares dos leitores e estimular que eles observassem primeiro a imagem visual, antes de ler o texto. Isso revela que os autores e editores tiveram a intenção de valorizar a imagem em relação aos textos explicativos.

\footnotetext{
${ }^{3}$ Diferentemente dos atuais padrões editoriais, que destinam um volume para cada ano letivo do Ensino Fundamental, os volumes analisados eram indicados para ser trabalhados em duas séries distintas, em conjunto com os outros volumes publicados para o estudo da História do Brasil e a História da Civilização. Dessa forma, pensamos que a Companhia Editora Nacional abria brechas para professores e alunos desenvolverem suas atividades escolares em um período marcado pelo impacto da Lei $\mathrm{n}^{\circ} 5.692$ de 1971, a qual estabeleceu a substituição das disciplinas História e Geografia pela disciplina Estudos Sociais no âmbito do primeiro grau.

4 “Sangrado" é o termo gráfico que caracteriza a impressão de uma imagem que avança os limites das bordas da página. A técnica de impressão sangrada somente foi desenvolvida após o surgimento de impressoras off-set.
} 
Ressaltamos que a estratégia de reprodução de imagens visuais também era utilizada em livros didáticos mais antigos, sobretudo os editados após a década de 1930. Nas obras didáticas do autor Joaquim Silva, destinadas ao ensino secundário de História e reconhecidas como as mais vendidas entre as décadas de 1940 e 1950, encontramos reproduções de pinturas, fotografias, gravuras e mapas (PINTO JR., 2010). As imagens visuais eram impressas em escalas de cinza, em dimensões reduzidas, como forma de ilustração de textos didáticos de História. O caráter ilustrativo das imagens visuais era evidente, pois invariavelmente as informações apresentadas por estas não tinham a pretensão de criar conexões diretas com os textos explicativos.

Sem dúvida, as obras da Coleção Sérgio Buarque de Holanda apresentavam recursos gráficos mais avançados na comparação com as produções editorias anteriores. Além das novas potencialidades técnicas apresentadas, outro aspecto importante contribuiu para a diferenciação da coleção para os padrões mercadológicos do período: as fotografias impressas em seus livros foram especialmente produzidas para essa finalidade (MÁsCULO, 2008). Sendo assim, um dos diferenciais dessa coleção é que, ao contrário das tradicionais obras didáticas de então, os textos explicativos de seus livros estabeleciam conexões diretas com a grande variedade de imagens visuais impressas que possuíam.

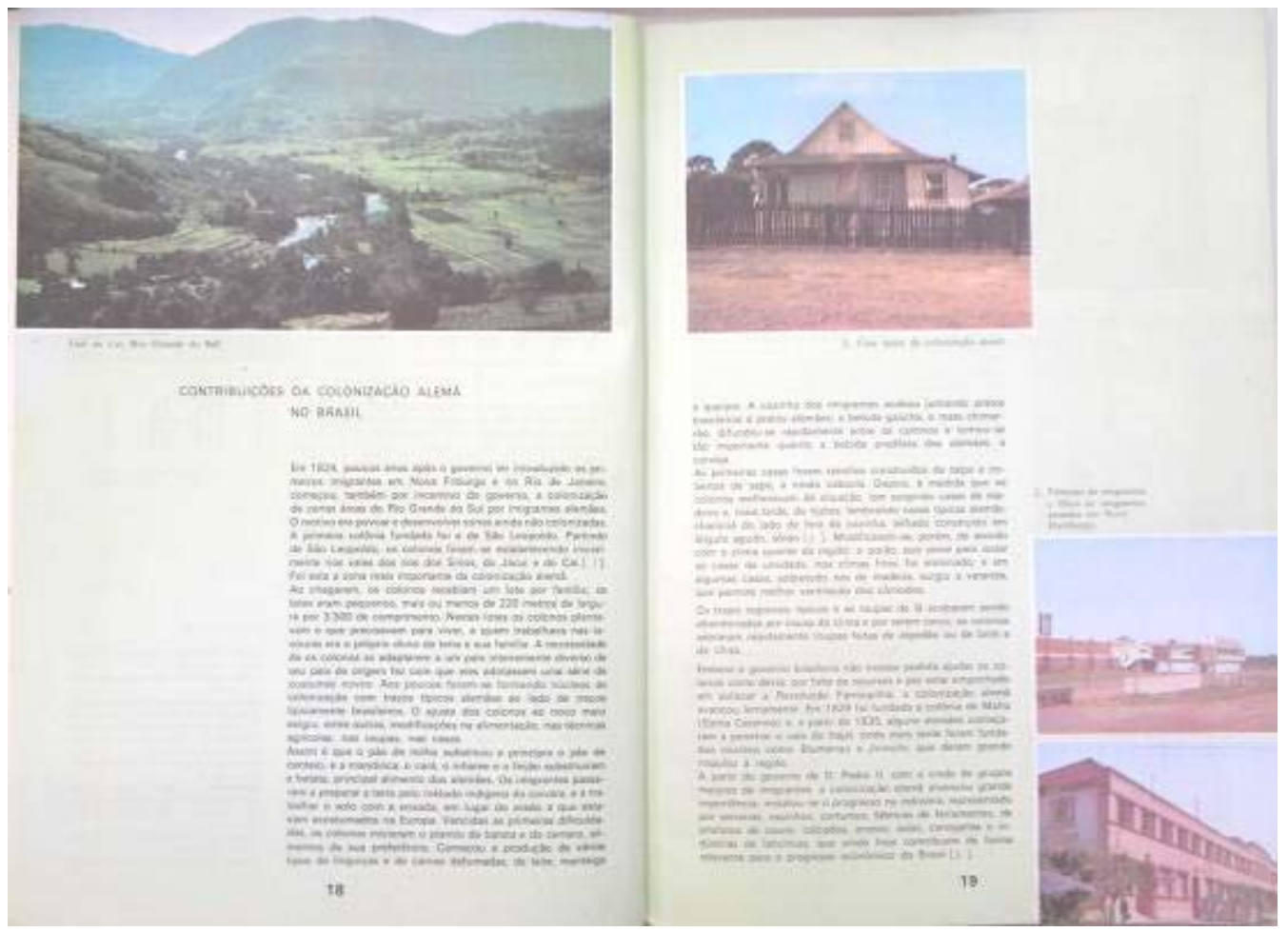

Figura 1 - Contribuições da colonização alemã no Brasil. Tema abordado através de textos e imagens nesta página dupla (dimensões da obra didática: 19 X 26 cm, reprodução reduzida).

Fonte: HOLANDA et al., 1972a, p. 18-19. 
A imagem visual da página 18 (Figura 1) representa um vale com montanhas ao fundo, no qual podemos avistar um rio margeado por uma mata ciliar. Ao lado da imagem do rio, reconhecemos campos agrícolas cultivados. Um olhar mais rápido dos leitores não identificaria de qual lugar se trata, pois a reprodução da fotografia não registra nenhuma característica visual singular pela qual eles poderiam localizar a sua origem. Para que os leitores fizessem o reconhecimento e a interpretação dessa iconografia, os autores lançaram mão da legenda. Esta traz os seguintes dizeres: “1. Vale do Caí, Rio Grande do Sul”. É importante notar que existe o número “ 1 ” na frente da legenda, e que ele se refere à numeração da imagem visual. O texto escrito do subtítulo do capítulo foi colocado logo abaixo da imagem e traz também informações que poderiam auxiliar os leitores na interpretação da imagem: “Contribuições da Colonização Alemã no Brasil”. Os leitores poderiam, então, construir relações entre a imagem fotográfica, o texto da legenda e o texto do subtítulo. Ou seja, a partir dessa montagem ele poderia criar associações entre os termos escritos: "Rio Grande do Sul” e “Colonização Alemã”, e os objetos representados na imagem visual.

Mas é no texto explicativo, localizado abaixo da imagem visual, que os autores concentram as informações que subsidiarão a interpretação dos leitores. O texto da legenda em associação com tal imagem orienta a compreensão dos leitores para o fato de que: "Partindo de São Leopoldo, os colonos foram se estabelecendo inicialmente nos vales dos rios dos Sinos, no Jacuí e do Caí [1]. Foi esta a zona mais importante da colonização alemã” (HOLANDA et al., 1972a, p. 18). Nota-se que a numeração que faz referência à imagem visual é colocada ao lado da palavra "Caí”, aparecendo também no texto explicativo. A intenção dessa numeração era produzir a associação entre o conteúdo do texto explicativo e o conteúdo da legenda. Chamamos a atenção para o fato de que esse procedimento direciona a interpretação da imagem visual. Já na página 19, observarmos que foram impressas mais três imagens visuais (nesse caso, reproduções de fotografias), que possuem dimensão inferior das impressas na página 18. A primeira foi impressa, acima da página, com as quatro bordas bem definidas. As outras duas foram apresentadas ao lado da coluna em que aparece o texto. Foram colocadas duas legendas: uma da imagem fotográfica impressa acima do texto e outra para as imagens visuais abaixo e ao lado direito da página. Temos também números nas legendas e nos textos escritos, que servem para os leitores realizarem as associações de significados. Essas formas de diagramação das imagens visuais são utilizadas ao longo de todos os livros da Coleção Sérgio Buarque de Holanda. Propomos que os autores e editores procuraram direcionar e estimular a interpretação das imagens visuais relacionando-as aos 
conteúdos dos textos. Ao optarem por esse procedimento, eles promoveram uma prática de leitura que valorizava a associação cognitiva das diferentes formas de emissão de informação (AUMONT, 2001; BARTHES, 1984), ou seja, a ligação entre a linguagem verbal e nãoverbal (BUENO, 2011). Aos leitores cabe, consequentemente, fazer o reconhecimento do teor da imagem visual, relacionando-o ao conteúdo dado pelo texto. Assim, a atribuição principal do texto é trazer informações, enquanto cabe à imagem possibilitar a visualização das formas dos objetos ou cenas descritas pelo texto.

Nessa mesma coleção, encontramos outra forma de composição gráfica de imagens visuais, que nos sugere uma concepção diferente de leitura de imagens para o período pesquisado. Nas páginas destinadas ao subtema "Cultura”, predominam imagens visuais de reproduções de pinturas, de diferentes tipos de esculturas e de prédios de diferentes estilos arquitetônicos. Em particular, nas páginas 20 e 21 (Figura 2) do livro História da Civilização, os autores apresentam o "Panorama cultural do início do século XIX”.

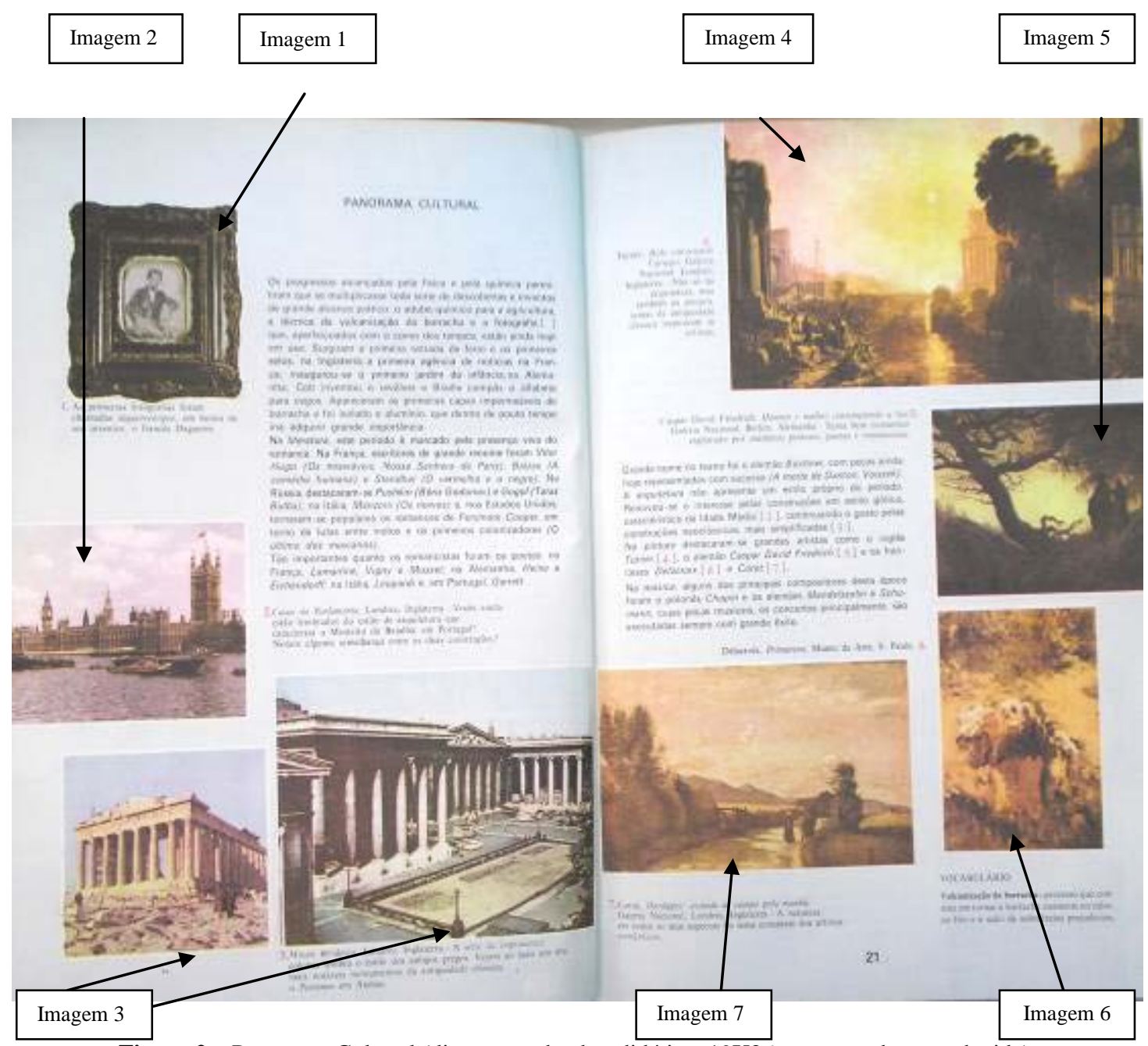

Figura 2 - Panorama Cultural (dimensões da obra didática: 19X26 cm, reprodução reduzida).

Fonte: HOLANDA et al., 1972b, p. 20-21. 
A página 20 exibe quatro reproduções de fotografias, uma de um daguerreótipo e três de prédios arquitetônicos distintos. $\mathrm{Na}$ página 21, são impressas quatro imagens de reprodução de pinturas de artistas românticos europeus. A imagem visual de número 1, que se encontra acima, na página 20, traz como legenda as seguintes informações: “1. As primeiras fotografias foram chamadas daguerreótipos, em honra de seu inventor, o francês Daguerre”. A numeração dessa legenda aparece, também, no texto explicativo: “Os progressos alcançados pela física e pela química permitiram que se multiplicasse toda sorte de descobertas e inventos de grande alcance prático: o adubo químico para a agricultura, a técnica da vulcanização da borracha e a fotografia. [1]" (HOLANDA et al., 1972b, p. 20). Sendo assim, os autores lançaram mão da mesma forma de associação de conteúdos que foi descrita anteriormente. Já nas imagens que trazem a numeração 2 e 3, nota-se que ocorreu uma mudança em relação às propostas de leitura apresentadas pelo livro.

Destacamos que a proposta a ser analisada é muito significativa, pois representa uma forma de abordagem e tratamento das imagens inovadora para aquela época. A imagem 2 é uma reprodução fotográfica que representa, ao fundo, o prédio do parlamento inglês, destacando-se o rio Tâmisa em primeiro plano. Sobre o rio é possível visualizarmos alguns barcos navegando. Essa imagem traz a seguinte legenda: “2. Casa do Parlamento, Londres, Inglaterra. - Vocês ainda estão lembrados do estilo de arquitetura que caracteriza o mosteiro da Batalha em Portugal? Notam alguma semelhança entre as duas construções?” As outras duas imagens (que trazem a numeração 3), também são reproduções fotográficas de edifícios com diferentes estilos arquitetônicos. Uma delas representa as ruínas do Partenon, em Atenas, e a outra a imagem do edifício do Museu Britânico, em Londres. Suas legendas identificam os dois prédios, propondo que os leitores façam uma comparação entre esses edifícios: “3. Museu Britânico, Londres, Inglaterra. A série de imponentes colunas lembra o estilo dos antigos gregos. Vejam ao lado um dos mais notáveis monumentos da antiguidade clássica, o Partenon em Atenas.”

A numeração da legenda faz a relação com o seguinte trecho do texto explicativo: “A arquitetura não apresenta um estilo próprio do período. Renovou-se o interesse pelas construções em estilo gótico característico da Idade Média [2], continuando o gosto pelas construções neoclássicas, mais simplificadas [3]” (HOLANDA et al., 1972b, p. 21). Notamos que os autores sugeriram que os leitores fizessem comparações entre dois documentos iconográficos, duas imagens visuais. Ao propor esse procedimento, eles criaram a possibilidade de os leitores compreenderem que as imagens visuais são portadoras de sinais que revelam as mudanças e as permanências dos estilos arquitetônicos. Consequentemente, os 
alunos e os professores (leitores explícitos) poderiam perceber que, a partir da análise da variação estética das formas arquitetônicas representadas, seria possível o reconhecimento dos diferentes tempos e espaços de produção dos objetos representados, posto que, em conexão, tais imagens e textos instauram uma narrativa e repertório específicos (BUENO, 2007). Destacamos que na década de 1970 não existia a preocupação dos autores e editores dos livros didáticos apresentarem as imagens visuais como documentos históricos. De forma precipitada, poderíamos julgar que os autores anteciparam essa prática didática ao estimular a leitura de imagens através da comparação entre duas fontes iconográficas. No entanto, é preciso relativizar essa conclusão. Segundo orientação do Manual do professor dessa coleção, os autores afirmavam que:

[...] o professor deve motivar os alunos valorizando técnicas de estudo: o estudo deve ser dirigido [...] $\mathrm{O}$ estudo dirigido leva o educando a desenvolver sua capacidade de identificação e escolha dos elementos mais significativos de um contexto, precisão de linguagem e objetividade no raciocínio com a assimilação de técnicas de associação, comparação, oposição e julgamento, etc. (HOLANDA et al., 1972b, p. 9 - Manual do professor).

É possível, então, concluirmos que, quando os autores desta coleção propuseram questões que possibilitavam a comparação entre as imagens (no caso da imagem visual 2 e das duas imagens identificadas com o número 3), eles esperavam que os leitores apenas identificassem e comparassem visualmente os três documentos iconográficos. Na época da produção desta coleção, realizar a comparação entre imagens visuais, em sala de aula, não significava propor que os alunos fizessem, necessariamente, uma contextualização histórica. Para que os leitores entendessem que as imagens visuais em questão eram documentos históricos, outras informações teriam que ser apresentadas pelos autores. Quando os alunos e professores comparassem essas imagens, eles teriam dificuldade em construir relações temporais e espaciais, pois estão ausentes das legendas as informações que revelam quando e como foram edificados os prédios representados em tais imagens visuais. Também não aparece na legenda o momento histórico que originou as fotografias reproduzidas nem a autoria delas. Em relação à imagem 2, os leitores teriam, ainda, outra dificuldade técnica, pois a imagem do Mosteiro da Batalha, em Portugal, não se encontra no mesmo livro. Os alunos e professores necessitariam lembrar as características físicas daquele prédio, que foi apresentado em outro volume da coleção. Com base nessas considerações, concluímos que o objetivo dos autores era propor que os alunos fizessem a identificação das características 
formais de cada um dos edifícios representados nas imagens visuais, ou seja, essas imagens serviriam para estimular e motivar os princípios de percepção visual dos leitores (ARNHEIM, 1989). Ao ler o texto do Manual do professor dessa coleção, encontramos alguns indícios que poderiam servir para comprovar esta conclusão. Os argumentos que justificam os objetivos pelos quais os autores utilizaram muitas imagens visuais concentram-se na ideia da motivação da percepção visual. A frase abaixo dos autores é reveladora de que “[...] suas ilustrações não enfeitam apenas o conteúdo, foram selecionadas e incluídas para ilustrar efetivamente o texto, dando-lhe vida e significado visual” (HOLANDA et al., 1972b, p. 9 - Manual do professor). Propomos que, para os autores dessa coleção, a concepção de leitura de imagens considerava que a imagem visual deveria proporcionar aos alunos a visualização e a complementação de informações trazidas pelo texto explicativo.

Ainda, ao analisarmos a página 21 (Figura 2), percebemos que são apresentadas quatro imagens visuais que são reproduções de pinturas de artistas românticos europeus. O texto principal que faz referência às tais reproduções se encontra também nessa página. Esse texto explica que essas imagens visuais representam pinturas de grandes artistas: "Na pintura destacaram-se grandes artistas como o inglês Turner [4], o alemão Caspar David Friedrich [5] e os franceses Delacroix [6] e Corot [7]” (HOLANDA et al., 1972b, p. 21). Os autores da coleção trataram de maneira especial às reproduções visuais derivadas de objetos de arte consagrados, porque para eles o teor de tais imagens é diferente do teor de imagens utilizadas para a representação e visualização de alguma cena histórica. Nota-se essa intenção quando fazemos as comparações entre as legendas explicativas das imagens de fotografias e imagens que são reproduções de obras de arte. As legendas das fotografias dos edifícios da página 20, por exemplo, identificam os prédios aos quais as imagens se referem, nomeando o objeto que está sendo representado. No caso das imagens de obras de arte, as legendas apresentam a autoria e o título das obras. No entanto, os autores se eximem da descrição dos objetos que aparecem representados na imagem. Em relação ao tipo de leitura proposto para as reproduções de obras de arte, acreditamos que os autores dão liberdade para os leitores interpretarem livremente os temas e as mensagens (ARNHEIM, 1989) que aparecem nas pinturas. Como são reproduções de objetos artísticos, deixam em aberto a possibilidade de os alunos e professores realizarem leituras que tragam diferentes informações e sentimentos, os quais, muitas vezes, não podem ser descritos apenas por palavras. Nesse caso, os autores aproximam-se das concepções de leitura de imagens que valorizam o distanciamento entre o processo de leitura de textos escritos e o reconhecimento das informações inscritas nas imagens visuais (FOUCAULT, 2000). 
Sendo assim, na Coleção Sérgio Buarque de Holanda, observamos esse tipo de elaboração editorial que procurava relacionar de maneira direta e explícita a "ilustração" "texto explicativo". Nela os autores lançavam mão de signos numéricos para fazer a associação entre os conteúdos dos textos explicativos e as informações trazidas pelas imagens visuais. Notamos que esse procedimento tendia a um certo cerceamento das possibilidades de leitura. Ainda, encontramos na mesma coleção outras duas propostas de leitura de imagens visuais. Uma propunha que os alunos fizessem exercícios de comparação entre duas imagens fotográficas de edifícios, com o objetivo de problematizar e comparar as informações trazidas pelas imagens. A outra privilegiava a elaboração de questões sobre as imagens visuais publicadas nos livros da coleção. Percebemos, considerando-se essas três propostas de leitura de imagens, que a coleção valorizava uma dada concepção e percepção de patrimônio cultural com base no teor e temática das imagens visuais que foram impressas e exploradas com mais vigor em seus livros. A visão de patrimônio focalizada na coleção privilegiava, sobretudo, os objetos pertencentes à cultura erudita, com ênfase particular àqueles com raízes europeias. Por isso, os livros didáticos da coleção apresentavam as reproduções de obras de arte consagradas, de fotografias e de bens arquitetônicos considerados de valor histórico a partir de tal referencial. Consideramos que a Coleção Sérgio Buarque de Holanda, muito além de cercear possibilidades de leitura, oportunizou que os leitores fizessem a identificação das diferenças estéticas entre os objetos representados nas iconografias.

\section{A Coleção de Borges Hermida}

Analisamos o livro didático História Moderna e Contemporânea, de autoria de Antonio José Borges Hermida, destinado à $8^{\text {a }}$ série do primeiro grau, publicado pela Companhia Editora Nacional em 1983. O autor era professor licenciado pela Faculdade Nacional de Filosofia do Rio de Janeiro e suas produções foram muito vendidas durante o Regime Militar. Com o início da Nova República, as transformações no mercado editorial e nas perspectivas do ensino de História fizeram as reconhecidas produções de Borges Hermida perderem espaço, ao ponto de não serem mais editadas a partir de 1993. Desde a primeira edição pela Companhia Editora Nacional, em 1959, até os anos finais da década de 1970, as

\footnotetext{
${ }^{5}$ No livro didático, a imagem visual, quando é utilizada no interior do texto principal dos capítulos, é chamada de “ilustração". Neles as ilustrações podem assumir diferentes funções, que correspondem a objetivos pedagógicos distintos. As imagens utilizadas nesses veículos de informação podem aparecer associadas a um texto escrito que procura criar uma afirmação verbal identificadora da informação não-verbal, ou, então, a imagem pode servir apenas para enfeitar e decorar o capítulo do livro.
} 
obras de Borges Hermida sofreram poucas mudanças em suas reedições. No início dos anos 80, seus livros didáticos foram totalmente reformulados, com o intuito de adaptá-los ao gosto e aos padrões da época. Nessa nova versão editorial foram acrescentadas muitas imagens visuais, os textos escritos foram sintetizados e o vocabulário sofreu um processo de controle editorial para adaptar-se à idade dos alunos. Os títulos dos livros didáticos que compunham a coleção de Borges Hermida também foram alterados, passando de Compêndios de História do Brasil e Compêndios de História Geral para História do Brasil, História Antiga e Medieval e História Moderna e Contemporânea. As dimensões dos livros também foram modificadas, passando de 19 X $26 \mathrm{~cm}$ para 21 X $28 \mathrm{~cm}$. Esse novo formato permitiu que fosse impressa uma grande quantidade de imagens visuais, com dimensões que superavam os espaços destinados aos textos escritos. O livro analisado apresenta os conteúdos que seguem uma cronologia linear, com ênfase em uma História factual e harmoniosa, priorizando os grandes vultos políticos, fundada em uma visão de História que pressupõe causas e consequências. A concepção de ensino de História desse livro valoriza sobremaneira a memorização dos conhecimentos produzidos pelo rigor científico da academia, tratando determinados documentos como expressões da verdade dos fatos históricos, enquanto elementos comprobatórios do texto.

Para Bittencourt (2001), Gatti Jr. (1998), Munakata, (1997) e Másculo (2008), dentre outros pesquisadores da área, os livros didáticos de Borges Hermida empregam as imagens visuais apenas como "ilustração"6. As origens desse tipo de diagramação encontram-se nos primeiros codex ilustrados. Estes foram os primeiros livros com imagens visuais que tinham o formato semelhante aos dos livros atuais e que as exibiam como adornos dos textos escritos (CHARTIER, 1998). O projeto gráfico do livro de Borges Hermida também serviu como modelo para muitos outros livros didáticos editados posteriormente. Seus capítulos foram estruturados da seguinte maneira: as páginas de abertura exibiam uma imagem que fazia referência à época que seria estudada. Essa imagem era seguida por um texto escrito segmentado em várias partes acompanhadas de subtítulos, os quais valorizavam, na grande maioria das vezes, aspectos políticos e econômicos da época que seria trabalhada no capítulo. Os textos escritos foram divididos em duas colunas; isso faria com que a leitura de cada linha escrita demorasse menos tempo, dando maior rapidez ao procedimento. As páginas finais dos capítulos apresentavam um resumo, aparecendo de forma destacada os itens do conteúdo do capítulo que deveriam ser estudados com mais cuidado e atenção pelos alunos. Em seguida,

\footnotetext{
${ }^{6}$ Nesse caso, os autores utilizam o termo “ilustração” para indicar que a imagem não traz uma informação adicional ao texto escrito ou serve apenas para enfeitar o texto escrito.
} 
aparecia impresso um box que exibia uma frase pronunciada por algum intelectual ou personagem representativo do período. O capítulo terminava com um questionário e, para respondê-lo, os alunos deveriam procurar e encontrar os conteúdos nos textos escritos.

O livro didático História Moderna e Contemporânea, de Borges Hermida, passou pelo processo de renovação editorial no ano de 1983. Na maioria de suas páginas foram impressas uma ou duas imagens visuais. As dimensões dessas imagens variavam bastante, ocupando desde um quarto até dois terços do espaço de impressão das páginas. Todas elas são coloridas. Foram reproduzidas imagens provenientes de pinturas, fotografias e desenhos realizados por ilustradores. Observa-se que aparecem muitas reproduções de pinturas consagradas e várias reproduções de retratos de personagens que se destacaram na história. Quase todas as imagens visuais vêm acompanhadas de pequenas legendas.

Pontuamos que a relação com o texto explicativo, muitas vezes, não é direta, como no caso da Coleção Sérgio Buarque de Holanda. Percebe-se, no livro de Borges Hermida, que as imagens visuais foram utilizadas apenas para decorar o texto escrito, pois não existe uma relação direta entre as mensagens que são reconhecidas na imagem e o conteúdo do texto explicativo. Nesse caso, a única forma de direcionamento da identificação do significado da imagem se dá pelo texto da legenda. A função de tal imagem decorativa poderia ser a de trazer alguma outra informação, para além das explicitadas nos textos explicativos. Porém, não existe qualquer referência que nos revele formalmente tal intenção do autor.

Na maior parte das vezes, as legendas do livro de Borges Hermida procuram narrar uma versão do fato que está sendo representado na imagem visual impressa, ou indicam o nome do personagem, ou o local que está sendo representado. As legendas normalmente são constituídas de uma frase afirmativa, a maioria delas não trazendo os dados relacionados ao documento que lhe deu origem, nem as datas, nem os dados dos autores ou a localização da obra original. Encontramos apenas algumas exceções que fugiram dessa regra. Estas ocorreram quando se tratava de imagens visuais que reproduz pinturas consagradas ou alguma gravura que foi impressa em um meio de comunicação (jornais e revistas de grande circulação na época) muito conhecido pelos historiadores. Para esse tipo de imagem era impresso o nome da pintura que a originou e o nome do artista que a produziu. Ao observarmos a página 55 do livro analisado (Figura 3), é possível a identificação de algumas das características citadas. A imagem dessa página marca o início do capítulo 10 do livro de Borges Hermida, que tem como título “A Independência dos Estados Unidos da América”. Nela, vemos a reprodução da pintura do retrato de George Washington, realizada por Gilbert Stuart, em 1796. 


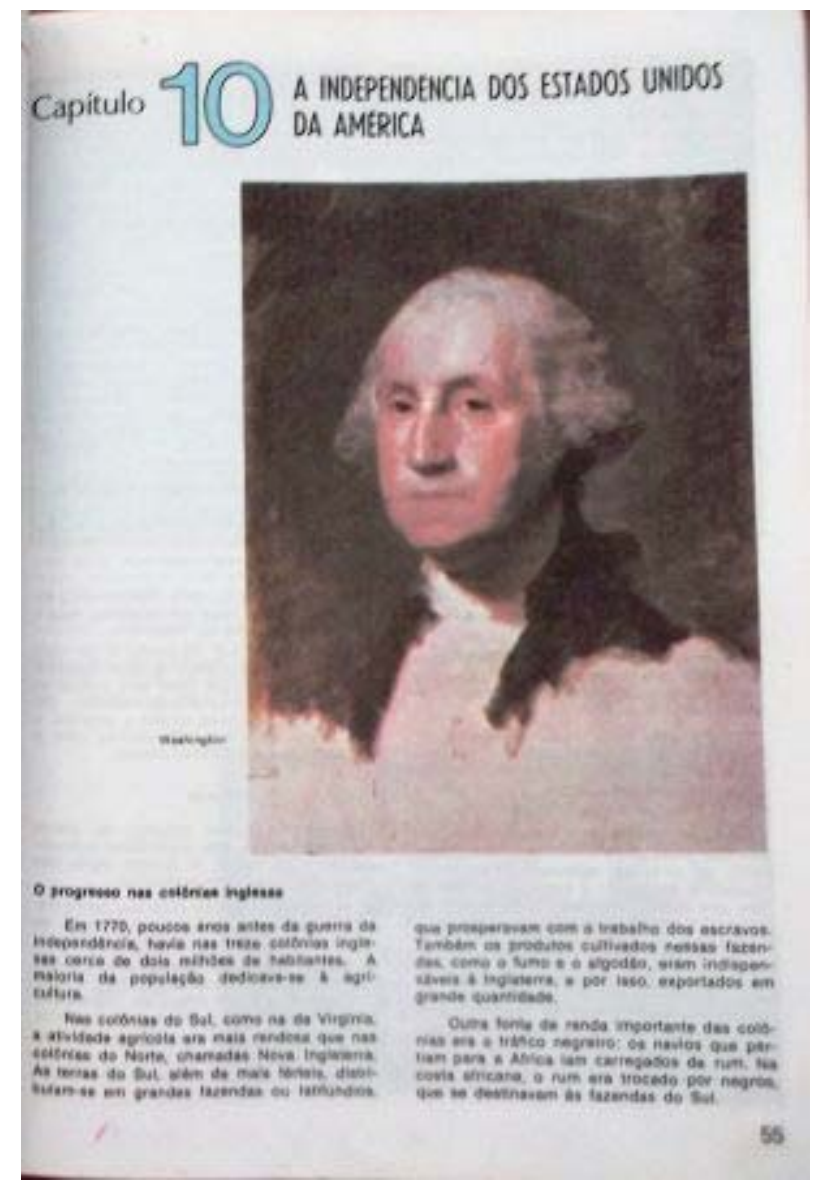

Figura 3 - Capítulo 10: A independência dos Estados Unidos da América (dimensões da obra didática: $21 X 28$ cm, reprodução reduzida).

Fonte: HERMIDA, 1983, p. 55.

A legenda - Washington - não indica nenhum dado relativo à obra que a originou; traz apenas a informação do nome do personagem representado. Esse tipo de legenda tem muita força como orientação de leitura, pois os leitores, ao visualizá-la, são levados a crer que realmente se trata do retrato desse personagem. A dimensão da imagem visual supera em muito a do texto escrito; isso poderia indicar que a imagem tem um grande valor de informação para o autor. No entanto, pelo que tudo indica, sua função era apenas a de motivar e atrair os olhares dos leitores, para que eles fizessem a leitura do texto escrito. Percebemos, também, que esse tipo de composição gráfica servia para marcar um tipo de pontuação, sinalizando o começo do capítulo. O texto explicativo que apresenta o conteúdo do capítulo, localizado logo abaixo da imagem, traz como informações principais as seguintes questões: "Em 1770 havia treze colônias inglesas na América. Existiam cerca de dois milhões de habitantes e a agricultura era a principal fonte de renda. As colônias do Sul diferenciavam-se das do Norte, pois no sul havia a escravidão negra” (HERMIDA, 1983, p. 55). Percebe-se, por essas informações, que o autor procura valorizar uma versão da história que prioriza a 
dimensão política, concebida como sinônimo do Estado e da economia. Nesse caso, os personagens históricos têm muita importância e por isso, o autor lança mão de uma ilustração representando o retrato de George Washington.

Propomos que tais iconografias teriam duas motivações. A primeira seria apresentar a informação de forma objetiva, com aparência de neutralidade. Nesse caso, quando os alunos fizessem o reconhecimento do retrato do personagem, eles deveriam aceitar que as características físicas representadas pela imagem eram precisas. Por isso, não existe qualquer margem para outro tipo de interpretação deles. A segunda seria conduzir os leitores do livro para um método de interpretação que procurava orientar todos para uma mesma e única conclusão.

Abordamos a obra História Moderna e Contemporânea para demonstrar que as formas tradicionais de uso de imagens visuais nos livros didáticos podem servir também como meios de informações que ultrapassam o significado exposto pelos textos escritos. No caso desse livro, as imagens visuais são apresentadas com legendas reduzidas, abrindo a possibilidade de os leitores realizarem interpretações baseados na identificação das formas que compõem tais imagens. Logo, é importante destacarmos que a escolha das imagens visuais impressas nos livros didáticos foi fruto de embates e conflitos, matizados por relações de poder acerca de uma dada concepção e percepção do ser, tema ou objeto que foi representado, além do que tais imagens produziram e produzem uma dada memória iconográfica ou visual (LE GOFF, 1990; MENESES, 2003) como se instaurassem um lugar de memória (NORA, 1993). Também é importante entendermos que, no processo de impressão, nem sempre as imagens visuais disponíveis para a publicação estão à disposição dos editores, quer por uma questão de direito autoral, quer pelo alto custo cobrado para a liberação de sua circulação impressa.

Pontuamos ainda que nesse livro de Borges Hermida não ocorria à relação direta de leitura entre os sentidos impressos nas imagens e os expostos pelos textos escritos. Por isso, entendemos que na atualidade esse tipo de proposta de leitura de imagens pode ser objeto de problematização, pois possibilita a realização de leituras anacrônicas em relação aos documentos visuais. É importante ressaltar, porém, que essa proposta de leitura abre espaço para o desenvolvimento de sensibilidades visuais no leitor, e estas são importantes para a construção dos saberes relacionados à identificação das diferenças estéticas que marcaram os distintos períodos históricos. 


\section{A coleção de livros de Gilberto Cotrim e Álvaro Duarte de Alencar}

Analisamos também um livro da coleção produzida por Gilberto Cotrim e Álvaro Duarte de Alencar, cujo título do volume é História Geral para uma geração consciente: Moderna e Contemporânea (Livro do professor), destinado à $8^{\text {a }}$ série do primeiro grau e publicado pela editora Saraiva em 1984. Esse livro pertence à primeira edição da coleção, composta por quatro livros textos não-consumíveis e um caderno de exercícios para cada série, além do Manual do professor ${ }^{7}$. O livro ficou conhecido como sendo apenas de autoria de Gilberto Cotrim, que foi professor de História do primeiro grau nos finais da década de 1970 e ao longo da década de 1980, e até os dias de hoje continua a fazer parte do conjunto de autores da editora Saraiva. Desde as primeiras edições, seus livros foram - e continuam sendo - muito adotados nas escolas brasileiras.

Essa coleção insere-se no processo de mudanças dos padrões editorias que ocorreu na primeira metade da década de 1980. Utilizou uma concepção de ensino que aborda o tempo histórico de forma cronológica e linear, mas valoriza o conceito de "luta de classes". Muito embora destaque ainda os personagens políticos, os heróis, as datas e os fatos comemorativos da História oficial. Os capítulos dos livros dessa coleção foram estruturados de maneira tradicional, dividindo os textos escritos em subtópicos que contemplavam temas da vida política dos diferentes países e períodos históricos estudados. Os textos foram apresentados em duas colunas paralelas; as linhas eram curtas e o espaçamento era adequado à visualização e leitura. Foram impressas de uma a três imagens visuais por página, as quais são reproduções de pinturas, esculturas, fotografias de prédios de diferentes estilos arquitetônicos ou então fotografias jornalísticas. No final dos capítulos foi reservada uma página para apresentação de um resumo histórico do período trabalhado e uma linha do tempo ilustrada.

Na análise comparativa entre os livros da Coleção de Sérgio Buarque de Holanda, de Borges Hermida e de Gilberto Cotrim e Álvaro Duarte de Alencar encontramos determinadas semelhanças, como também mudanças nas formas de apresentação das imagens visuais adotadas. A maioria das páginas do livro de Cotrim e Alencar apresenta imagens visuais; no entanto, suas dimensões são menores, se comparadas às utilizadas nos livros de Holanda e Hermida. Os espaços das páginas destinados às imagens visuais diminuem, abrindo mais

\footnotetext{
${ }^{7}$ Os "Manuais do professor" começaram a ser editados na década de 1970, podendo ser apresentados como fascículos à parte e vindo separados do livro didático ou fazendo parte do livro. Nesse último caso, o livro didático é identificado como "Livro do professor", pois apresenta o livro didático e o manual do professor num mesmo material. Os manuais podem trazer sugestões de práticas de ensino, formas de uso do livro didático, modelos de planejamentos, etc. Um dos objetivos desses manuais é auxiliar na formação continuada dos professores.
} 
espaço para os textos escritos. No início da década de 1980, os livros didáticos começaram a apresentar textos mais longos em relação aos produzidos na década de 1970. Essa forma de apresentação das imagens visuais representou uma das tendências dos projetos gráficos da época. Esse procedimento de diagramação permanece ainda hoje. Nota-se, também, que, a partir da década de 1980, a presença de desenhos de ilustração diminuiu drasticamente.

O livro de Cotrim e Alencar possui muitas reproduções de pintura quando aborda temas relativos aos fatos históricos que ocorreram no período anterior ao século XIX. Quando passa a abordar temas relativos aos acontecimentos históricos posteriores ao século XIX, as imagens de reproduções fotográficas são predominantes nas páginas. Diferentemente das imagens adotadas pela Coleção Sérgio Buarque de Holanda, os livros de Cotrim e Alencar utilizam muitas imagens originadas de fotografias jornalísticas para registrar patrimônios arquitetônicos produzidos nos séculos anteriores.

Observando ainda a página 14 (Figura 4) do livro de Cotrim e Alencar, podemos perceber como diminuem as dimensões das imagens visuais e como os textos escritos ganharam mais espaço na composição das manchas gráficas. É possível visualizar que a coluna da esquerda, no alto da página, apresenta um texto escrito e a sua direita encontra-se a reprodução de um retrato impresso em preto e branco. Este traz a seguinte legenda: "Henrique VII, o fundador da Dinastia Tudor”. No texto explicativo encontramos a seguinte afirmação:

Na Inglaterra o absolutismo teve início com o rei Henrique VII (1485-1509), fundador da Dinastia Tudor, que assumiu o poder quando terminava uma longa guerra entre diferentes grupos da nobreza (Guerra das Duas Rosas 1455-1485) (COTRIM; ALENCAR, 1984, p. 14).

As informações que se encontram no texto explicativo podem ser associadas ao conteúdo da legenda. Logo abaixo desse texto, destaca-se um box, onde é reproduzida a imagem de documento histórico, escrito manualmente, e que traz a seguinte legenda: "fac simile da Carta Magna”. Desse ponto em diante aparece um texto que faz referência a essa imagem, explicando o que foi a Carta Magna:

O parlamento Inglês tem suas origens no século XII, quando os barões, os cavaleiros e os mercadores ricos das cidades uniram-se contra o aumento dos tributos declarados pelo rei João Sem-Terra (1199-1216). Como resultado dessa união, o rei foi obrigado a assinar, em 1215, um documento conhecido como Magna Carta (COTRIM; ALENCAR, 1984, p. 14). 


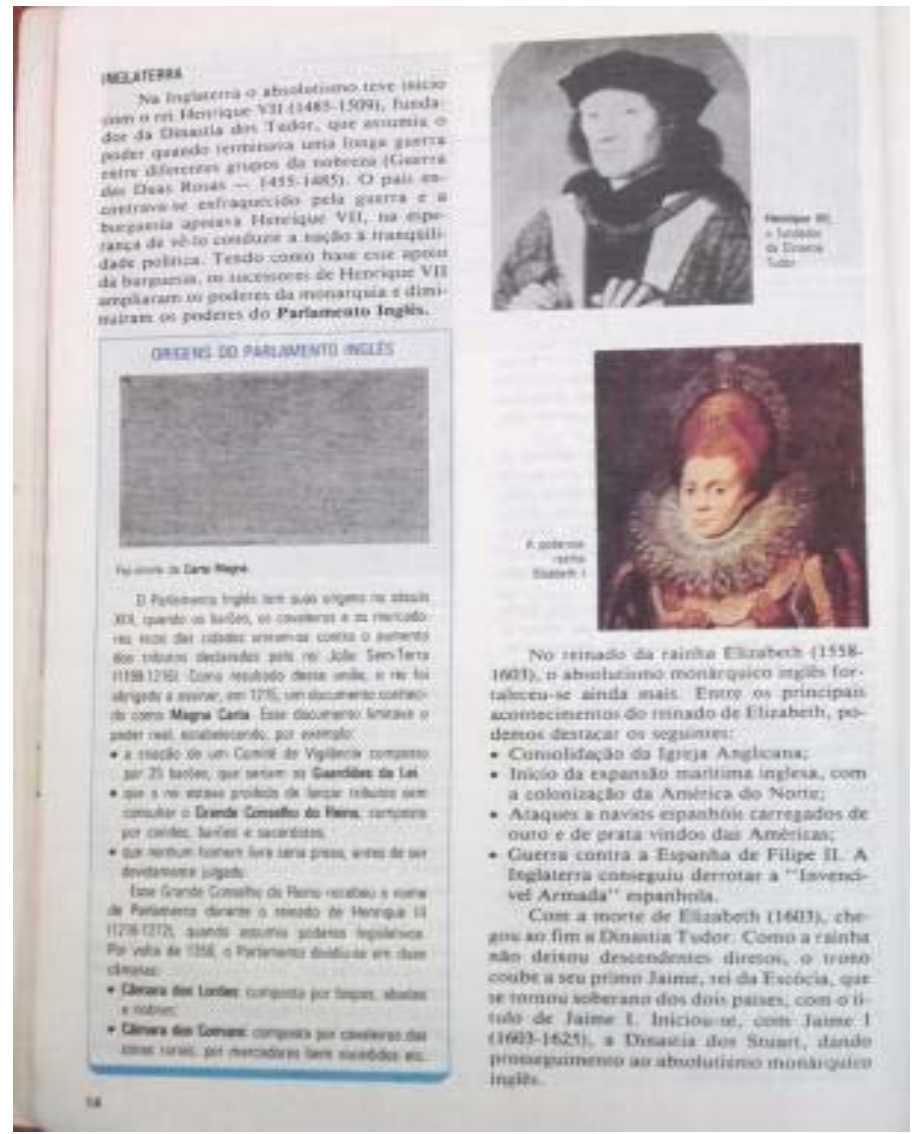

Figura 4 - Capítulo VIII: O absolutismo (dimensões da obra didática: 21 X28 cm, reprodução reduzida). Fonte: COTRIM; ALENCAR, 1984, p. 14

A terceira imagem que compõe a mesma página é a reprodução da pintura de um retrato que apresenta a seguinte legenda: “A poderosa rainha Elizabeth I”. O texto explicativo da página faz referência ao reinado dessa rainha. Entretanto, não aparece impressa nenhuma informação que revele a origem do documento, o local onde ele se encontra na atualidade, a data de sua produção ou sua autoria $^{8}$. É possível perceber, nesse caso, como a forma de elaboração da legenda é semelhante à utilizada no livro de Borges Hermida.

Em relação à proposta de leitura das imagens visuais, reconhecemos que existe uma semelhança da forma editorial dos livros da Coleção Sérgio Buarque de Holanda com os de Cotrim e Alencar. Nota-se que o texto explicativo procura trazer informações sobre a imagem, municiando os leitores na interpretação da mesma. Por outro lado, não é utilizado nenhum “procedimento indicativo” que permita a relação entre a imagem e os conteúdos do texto escrito, como nos livros da Coleção Sérgio Buarque de Holanda, muito embora os leitores

\footnotetext{
${ }^{8}$ A partir da instituição das formas de avaliação do PNLD, em 1999, todas as imagens impressas nos livros didáticos teriam que apresentar os dados de produção, autoria e localização da obra original, sob pena de passarem a não compor a lista de compras do Estado. Apesar da implementação dessa norma de avaliação, encontramos ainda hoje imagens impressas nos livros didáticos que não apresentam essas informações aos leitores.
} 
possam, mesmo assim, construir essas relações. Percebemos, nesse caso, que as imagens visuais permanecem sendo utilizadas como mero elemento decorativo.

Nos livros de Gilberto Cotrim e Álvaro Duarte de Alencar, identificamos que foram construídas legendas explicativas mais bem elaboradas, contribuindo para o desenvolvimento das formas de leitura que valorizavam a conexão entre textos escritos e imagens visuais. Os autores indicavam nas legendas os dados da autoria das imagens originais e, em diversas partes do livro didático, apresentavam informações sobre a localização da obra que foi reproduzida. Esse tipo de tratamento destinado às imagens impressas nos livros didáticos passou a ser incentivado pelas normas do PNLD a partir dos últimos anos da década de 1990, tornando-se uma prática editorial recorrente até nossos dias. Os intelectuais responsáveis pela elaboração das referidas normas justificam que a apresentação dos dados relativos à produção da imagem abre a oportunidade de os leitores buscarem o reconhecimento dos tempos, espaços e sujeitos envolvidos no ato produtivo. Nesse sentido, a leitura das imagens visuais pode ter ampliado a possibilidade de compreensão de sua historicidade, bem como a identificação de determinadas intenções autorais no momento da sua produção.

\section{Considerações finais}

Compreendemos, com base nas análises dos livros didáticos focalizados, que as propostas de leitura de imagens visuais com fins didáticos tinham o objetivo de estimular a prática de leitura de textos no ensino de História. Caberia aos professores e alunos observarem as informações fornecidas pelos textos, utilizarem as imagens visuais para identificar cenas de determinados fatos históricos, as características pessoais dos personagens representados, as formas de se vestir ou os atributos que representavam o poder dos indivíduos que se destacaram no período estudado. Pela intermediação dos textos, seria possível, ainda, identificar espaços geográficos, tempos distintos e formas de expressão artística, dentre outras possibilidades. Ao cotejarmos os livros didáticos produzidos na atualidade, notamos que essa forma de tratamento de imagens visuais ainda é usual, muito embora reconheçamos que foi a partir das décadas de 1970 e 80, quando determinados autores e editores começaram a propor diferentes procedimentos de leituras de imagens visuais nos livros didáticos, que se constituíram saberes editoriais e escolares, os quais serviram de base teórica e prática para desenvolvimento de novas propostas que emergiram nos livros didáticos das décadas posteriores. 
Acreditamos que as imagens visuais impressas nos livros didáticos de História destinados ao ensino fundamental nos dias atuais podem ser utilizadas para promover uma educação estética dos sentidos ${ }^{9}$, potencializando a atuação dos professores com o objetivo de estimular a formação de memórias iconográficas ou visuais em seus alunos, contribuindo, também, para a construção de práticas que possibilitem a fruição, o entendimento e a contextualização das informações que se relacionam aos bens culturais originais - suas características formais, dimensões, materiais utilizados, técnica, autoria, período, localização na atualidade.

Finalmente, entendemos que os processos de leitura de imagens visuais construídos a partir do período analisado, em certa medida limitaram as interpretações subjetivas que elas poderiam suscitar nos leitores. Dessa forma, instituíram métodos que procuravam direcionar os processos de interpretação das imagens visuais numa tentativa de criar propostas metodológicas que se baseavam no reconhecimento dos signos representados nas imagens privilegiadas, devendo aqueles ser associados aos conteúdos dos textos. E essa forma de leitura vem sendo sedimentada ao longo dos anos, como a metodologia mais correta de leitura de imagens visuais.

\footnotetext{
${ }^{9}$ Neste caso, os professores poderiam desenvolver atividades interdisciplinares com a área de Artes, propondo que os alunos realizassem atividades de contextualização temporal a partir de atividades plásticas com as imagens. Existem, atualmente, diferentes metodologias desenvolvidas pela área de ensino de Artes que procuram trabalhar a criatividade e a sensibilidade dos alunos, bem como, possibilitam uma educação do olhar e o reconhecimento do tempo de produção das obras de arte.
} 


\section{Referências}

ARNHEIM, Rudolf. Arte e percepção visual: uma psicologia da visão criadora. São Paulo: EDUSP; Pioneira, 1989.

AUMONT, Jacques. A imagem. Campinas: Papirus, 2001.

BARTHES, Roland. A câmara clara. Rio de Janeiro: Nova Fronteira, 1984.

BITTENCOURT, Circe. M. F. Livros didáticos entre textos e imagens. In: (org.). O saber histórico na sala de aula. São Paulo: Contexto, 2001.

BUENO, João B. G. Imagens visuais nos livros didáticos: permanências e rupturas nas propostas de leitura (Brasil décadas de 1970 a 2000). 2011. Tese (Doutorado em Educação) Faculdade de Educação, Universidade Estadual de Campinas, Campinas (SP), 2011.

BUENO, Maria de Fátima G. O corpo e as sensibilidades modernas: Bragança (1900-1920). 2007. Tese (Doutorado em Educação) - Faculdade de Educação, Universidade Estadual de Campinas, Campinas (SP), 2007.

CHARTIER, Roger. A aventura do livro: do leitor ao navegador. Conversação com Jean Lebrun. São Paulo: Fundação da Editora da UNESP, 1998.

COTRIM, Gilberto; ALENCAR, Alencar D. História geral para uma geração consciente: moderna e contemporânea (Livro do professor). São Paulo: Saraiva, 1984.

DEBORD, Guy. A sociedade do espetáculo. Rio de Janeiro: Contraponto, 2000.

FERREIRA, O. M. C.; SILVA JR., P. D. Recursos audiovisuais para o ensino. São Paulo: EPU, 1975.

FOUCAULT, Michel. As palavras e as imagens. Ditos e escritos II. Rio de Janeiro: Forense Universitária, 2000.

GATTI JUNIOR, Décio. Livro didático e ensino de história: dos anos sessenta aos nossos dias. 1998. Tese (Doutorado em Educação: História, Política, Sociedade). Pontifícia Universidade Católica de São Paulo, São Paulo, 1998.

HERMIDA, A. J. B. História moderna e contemporânea - 8ª série. São Paulo: Companhia Ed. Nacional, 1983.

HOLANDA, Sergio B. et al. História do Brasil: da independência aos nossos dias. Curso moderno. São Paulo: Companhia Ed. Nacional, 1972a.

1972b. . História da civilização. Curso moderno. São Paulo: Companhia Ed. Nacional,

LE GOFF, Jacques. História e memória. Campinas: Editora da UNICAMP, 1990. 
MASCULO, José C. A Coleção Sergio Buarque de Holanda: livros didáticos e ensino de História. 2008. Tese (Doutorado em Educação: História, Política, Sociedade). Pontifícia Universidade Católica de São Paulo, São Paulo, 2008.

MENESES, Ulpiano T. B. Fontes visuais, cultura visual, história visual. Balanço provisório, propostas cautelares. Revista Brasileira de História, São Paulo, v. 23, n. 45, p. 11-36, 2003.

MUNAKATA, Kazumi. Produzindo livros didáticos e paradidáticos. 1997. Tese (Doutorado em História e Filosofia da Educação). Pontifícia Universidade Católica de São Paulo, São Paulo, 1997.

NORA, Pierre. Entre memória e história. A problemática dos lugares. Projeto História, São Paulo, n. 10, p. 7-28, dez. 1993.

OLIVEIRA, João B. A. Os livros descartáveis: exigência pedagógica ou apenas um bom negócio? Cadernos de Pesquisa, São Paulo, n. 44, p. 90-94, fev. 1983.

PINTO JR., Arnaldo. Professor Joaquim Silva, um autor da história ensinada do Brasil: livros didáticos e educação moderna dos sentidos (1940-1951). 2010. Tese (Doutorado em Educação) - Faculdade de Educação, Universidade Estadual de Campinas, Campinas (SP), 2010. 